\title{
Geologic map of the Devore 7.5' quadrangle, San Bernardino County , California
}

By D.M. Morton ${ }^{1}$ and J.C. Matti ${ }^{2}$

Digital preparation by G. Morton ${ }^{1}$, C. Koukladas ${ }^{1}$, and P.M. Cossette ${ }^{3}$

Prepared in cooperation with

CALIFORNIA DIVISION OF MINES AND GEOLOGY

Open-File Report OF 01-173

2001

Any use of trade, product, or firm names is for descriptive purposes only and does not imply endorsement by the U. S.

Government. This database, identified as "Geologic map of the Devore 7.5' quadrangle, San Bemardino County, California " has been approved for release and publication by the Director of the USGS.

\section{U. S. DEPARTMENT OF THE INTERIOR}

U. S. GEOLOGICAL SURVEY

${ }^{1}$ Western Earth Surface Processes Team, U.S. Geological Survey

University of California, Riverside, CA 92521

${ }^{2}$ Western Earth Surface Processes Team, U.S. Geological Survey 920 North Park Avenue, Tucson, AZ 85719-5035

${ }^{3}$ U.S. Geological Survey

904 West Riverside Avenue, Spokane, WA 99201 


\title{
TABLE OF CONTENTS
}

\author{
Introduction \\ General \\ How to obtain paper plots \\ Database contents \\ Data package \\ Plot package \\ Other files \\ Software utilities \\ How to obtain the digital files \\ How to extract the geologic map database from the tar file \\ Digital database \\ PostScript plot files \\ Portable Document Format (.pdf) files \\ How to convert the ARC/INFO interchange (export) files \\ Digital geologic map specifications \\ Digital and geologic compilation of geologic map \\ Base map \\ Spatial resolution \\ Map accuracy standards \\ Database specifics \\ General \\ Lines \\ Polygons \\ Points \\ References \\ Appendix I
}

\section{INTRODUCTION}

\section{General}

Open-File Report OF 01-173 contains a digital geologic map database of the Devore 7.5' quadrangle, San Bernardino County, California that includes:

1. ARC/INFO (Environmental Systems Research Institute, http://www.esri.com) version 7.2.1 coverages of the various components of the geologic map

2. A PostScript file to plot the geologic map on a topographic base, and containing a Correlation of Map Units diagram, a Description of Map Units, an index map, and a regional structure map.

3. Portable Document Format (.pdf) files of:

a. This Readme; includes an Appendix, containing metadata details found in devre_met.txt.

b. The same graphic as plotted in 2 above. (Test plots from this .pdf do not produce 1:24,000-scale Maps. Adobe Acrobat pagesize settings controls map scale.)

The Correlation of Map Units and Description of Map Units is in the editorial format of USGS Miscellaneous Investigations Series (I-series) maps but has not been edited to comply with I-map standards. Within the geologic map data package, map units are identified by standard geologic map criteria such as formation-name, age, and lithology. Even though this is an author-prepared report, every attempt has been made to closely adhere to the stratigraphic nomenclature of the U. S. Geological Survey. Descriptions of units can be obtained by viewing or plotting the .pdf file ( $3 \mathrm{~b}$ above) or plotting the postscript file ( 2 above). If roads in some areas, especially forest roads that parallel topographic contours, do not show well on plots of the geologic map, we recommend use of the USGS Devore 7.5' topographic quadrangle in conjunction with the geologic map. 
This README file describes the digital data, such as types and general contents of files making up the database, and includes information on how to extract and plot the map and accompanying graphic file. Metadata information can be accessed at http://geo-nsdi.er.usgs.gov/cgi-bin/publication?map-of and are included in Appendix I of the Readme.

\section{HOW TO OBTAIN PAPER PLOTS}

For those having access to large-format plotters such as HP650C, HP755C, and HP2500C, plots may be made directly from the included plot file. For those needing paper plots of the geologic map and accompanying text, but who do not have access to large-format plotters, please contact the U.S. Geological Survey Plot-on-demand facility.

Phone: 1-800-USA-MAPS (1-800-872-6277)

\section{DATABASE CONTENTS}

The files constituting the geologic map database of this Open-File Report are listed below along with the interchange files from which they are extracted.

\section{Data Package}

All files listed below are in a compressed tar file named devre.tar.gz (2.8 MB); see section below titled, SOFTWARE UTILITIES.

\begin{tabular}{|c|c|c|}
\hline$\frac{\text { ARC/INFO }}{\text { interchange files }}$ & $\frac{\text { Devore }}{\text { files }}$ & $\underline{\text { Contains }}$ \\
\hline devre_geo.e00 & devre_geo & $\begin{array}{l}\text { Contacts, faults, geologic unit } \\
\text { labels }\end{array}$ \\
\hline $\begin{array}{l}\text { devre_str.e00 } \\
\text { devre_ldr.e00 }\end{array}$ & $\begin{array}{l}\text { devre_str } \\
\text { devre_ldr }\end{array}$ & $\begin{array}{l}\text { Attitudes and their dip values. Dip } \\
\text { values plotted as annotation. } \\
\text { unit label leaders, fault names }\end{array}$ \\
\hline $\begin{array}{l}\text { lines.rel.e00 } \\
\text { points.rel.e00 } \\
\text { scamp2.shd.e00 }\end{array}$ & $\begin{array}{l}\text { lines.rel } \\
\text { points.rel } \\
\text { scamp2.shd }\end{array}$ & $\begin{array}{l}\text { Line dictionary } \\
\text { Point dictionary } \\
\text { SCAMP shade set }\end{array}$ \\
\hline
\end{tabular}

The directory, info/, is produced in the process of importing interchange files to ARC coverages in ARC/INFO. The devre (Devore) info/ directory contains:

Feature Attribute tables

\begin{tabular}{|c|c|}
\hline devre_geo.pat & Polygon attribute table \\
\hline $\begin{array}{l}\text { devre_geo.aat } \\
\text { devre_ldr.aat }\end{array}$ & Arc attribute tables \\
\hline devre_str.pat & Point attribute table \\
\hline
\end{tabular}

$\underline{\text { INFO data tables }}$

lines.rel

points.rel
Dictionary, contains all SCAMP line codes (Matti and others, 1998a)

Dictionary, contains all SCAMP point codes (Matti and others, 1998b) 
$\underline{\text { Raster file }}$

devre.tif $\underline{\text { Resultant image }}$

Devore

base map
Contains

Topographic base from 500dpi scan of USGS

Devore 7.5' quadrangle, 1966

\section{Plot Package}

PostScript plot files of the geologic map and CMU/DMU; please see section below titled, SOFTWARE UTILITIES for additional information.

$\begin{array}{lll}\text { Compressed file } & \text { Resultant image } & \underline{\text { Contains }} \\ \text { devre_map.ps.gz } & \text { devre_map.ps } & \begin{array}{l}\text { PostScript plot file of geologic map and } \\ \text { CMU/DMU }\end{array}\end{array}$

PostScript files are compressed UNIX files requiring gzip to uncompress them.

The uncompressed PostScript file devre_map.ps will plot a 1:24,000 scale, full color geologic map of the Devore quadrangle on a topographic base. A detailed CMU diagram, a DMU, and a regional structure map are included on the sheet. This sheet is in the editorial format of the U.S. Geological Survey's Miscellaneous Investigations (I) map series, and is approximately 45 X 32 inches in size. The map sheet has been successfully plotted on HewlettPackard large-format plotters, models HP650C, HP755CM, and HP2500C.

\section{Other files}
Readme.pdf
This document in .pdf format
devre_map.pdf
Geologic map, DMU, CMU, and sketch maps

\section{SOFTWARE UTILITIES}

Files which have .gz file extension were compressed using gzip. Gzip utilities are available free of charge via the internet at the gzip home page, http://www.gzip.org

The data package is additionally bundled into a single tar (tape archive) file. Individual files must be extracted using a tar utility, available free of charge via the internet through links on the Common Internet File Formats page, http://www.matisse.net/files/formats.html. One such utility is WinZip, available at http://www.winzip.com (WinZip can also decompress files).

Files in the plot package have been prepared to produce optimum plots using the shade, and marker sets listed below. The marker and line sets may be obtained at the web site http://wrgis.wr.usgs.gov/docs/ncgm/scamp/scamp.html. Geoage font group may be obtained at the web site
Server:
UserID:
Password:
onyx.wr.usgs.gov
Directory:
anonymous
Your e-mail address
pub/wpg/supplies/geoage

geoscamp2.lin
geoscamp2.mrk
scamp2.shd
geology2.shd
Geoage font group
Lines

Points

Colors

Patterns

Geologic Age Symbols 


\section{HOW TO OBTAIN THE DIGITAL FILES}

The export files, and subsequently the data and plot files, constituting the geologic map database of this Open-File Map may be obtained in two ways, both over the Internet.

1. The files can be obtained via the Web from Western Region Geologic Information Server. Go to the web page at http://geopubsis.wr.usgs.gov/open-file/of01-173 and follow the directions to download the files.

2. The files can also be obtained by anonymous ftp over the Internet from wrgis.wr.usgs.gov. The files are located in the directory /pub/open-file/of01-173. Be sure to use binary transfer mo de or ASCII mode for individual .e00 files (ARC interchange file format).

3. Metadata can be obtained at http://geo-nsdi.er.usgs.gov/cgi-bin/publication?open-file

\section{HOW TO EXTRACT THE GEOLOGIC MAP DATABASE FROM THE TAR FILE}

After downloading the files, they must be uncompressed using a gzip utility such as gzip itself or WinZip. The data files must then be extracted using a tar utility.

This process will create a directory, devre/, that contains the ARC/INFO interchange files and supporting files. The directory should contain the following files:

devre/

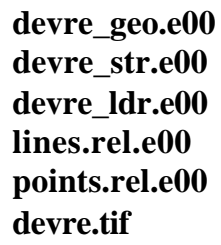

The following are not included in the database tar file, and are downloaded separately

devre_map.ps

Readme.pdf

This document in .pdf format

devre_map.pdf

Geologic map, DMU, CMU, and sketch maps

\section{PostScript plot files}

Make a $22 \mathrm{MB}$ uncompressed file, devre_map.ps by typing gzip -d devre_map.ps.gz (or use gzip utility of choice)

\section{Portable Document Format (.pdf) files}

PDF files are not stored as gzip files. They are accessed using Adobe Acrobat Reader software, available free from the Adobe website http://www.adobe.com. Follow instructions at the website to download and install the software. Acrobat Reader contains an on-line manual and tutorial.

\section{HOW TO CONVERT THE ARC/INFO INTERCHANGE (EXPORT) FILES}

The ARC interchange (.e00) files are converted to ARC coverages using the ARC command IMPORT.

ARC interchange files can also be read by some other Geographic Information Systems, including ArcView (ESRI) and MapInfo (http://www.mapinfo.com) (Environmental Systems Research Institute, Inc, 1991). Please consult your GIS documentation to see if you can use ARC interchange files and the procedure to import them. 


\section{DIGITAL GEOLOGIC MAP SPECIFICATIONS}

\section{Digital and geologic compilation of geologic map}

The geologic map was compiled from 1:24,000 geologic mapping on aerial photographs and topographic quadrangle maps, transferred visually to a base-stable cronoflex copy of the Devore 7.5' quadrangle, and the linework scribed from the cronoflex map. The scribe guide was used to make a 0.007 "-thick blackline clear-film, from which lines and points were hand-digitized at the USGS Riverside GIS lab. Lines, points, and polygons were subsequently edited at the USGS Spokane GIS lab using standard ARC/INFO commands. Digitizing and editing artifacts significant enough to display at a scale of 1:24,000 were corrected.

\section{Base map}

The base map image (devre.tif, Geotiff format) was prepared by scanning a scale-stable clear film of the U.S Geological Survey, 1:24,000 Devore 7. 5' quadrangle (1971) topographic map. Scanning was done using an Anatech Eagle 4080 monochrome 800 dpi scanner; at a resolution of 500 dpi. The raster scan was converted to a monochromatic image in ARC/INFO, and registered and rectified to the Devore 7.5' quadrangle. No elements of the base layer are attributed. The base map is provided for reference only.

\section{Spatial resolution}

Use of this digital geologic map database should not violate the spatial resolution of the data. Although the digital form of the data removes the constraint imposed by the scale of a paper map, the detail and accuracy inherent in map scale are also present in the digital data. The fact that this database was edited at a scale of 1:24,000 means that higher resolution information is not generally present in the dataset. Plotting at scales larger than 1:24,000 will not yield greater real detail, although it may reveal fine-scale irregularities above the intended resolution of the database. Similarly, although higher resolution data is incorporated at some places, the resolution of the combined output will be limited by the lower resolution data.

\section{Map accuracy standards}

Until uniform National geologic map accuracy standards are developed and adopted, lines and points on SCAMP 1:24,000 scale geologic maps that are located to within 15 meters, relative to accurately located features on the base map, are considered to meet map accuracy standards. Dashed lines, indicated in the database coding as not meeting map accuracy standards, are generally located to within 30 meters, relative to accurately located features on the base map.

\section{Database specifics}

General-The map database consists of ARC/INFO format coverages which are stored in polyconic projection (Table 1), and a series of data tables. Digital tics define a 7.5-minute grid of latitude and longitude in the geologic coverages corresponding to the 7.5-minute tic grid on the topographic base map.

Table 1-Map Projection

$\begin{array}{ll}\text { Projection } & \text { Polyconic } \\ \text { Datum } & \text { NAD27 } \\ \text { Zunits } & \text { No } \\ \text { Units } & \text { Meters } \\ \text { Spheroid } & \text { Clark } 1866 \\ \text { X shift } & 0.0000000000 \\ \text { Y shift } & 0.0000000000 \\ \text { Parameters } & -1172615.000 \text { longitude of central meridian } \\ & 340730.000 \text { latitude of projection's origin } \\ & 0.00000 \text { false easting (meters) } \\ & 0.00000 \text { false northing (meters) }\end{array}$


The content of the geologic database can be described in terms of feature classes that include lines, points, and areas that comprise the map. See the metadata text file (Appendix I) for detailed descriptions. Although Version 1.0 of the Devore 7.5' quadrangle does not contain coded, detailed, geologic attribute data, the items L-TAG (lines) and PTAG (structural point data) do serve as relate items allowing users to establish a relate environment with and access to complete descriptions of the geologic entities contained in the line and point dictionaries (Matti and others, 1998a, 1998b). The following is an example of how to establish a simple relate environment and the ARC/INFO dialogue the user will encounter:

At the Arc prompt, type: relate add

Dialogue for ADD

$\begin{array}{ll}\begin{array}{l}\text { Relation name: } \\ \text { Table identifier: }\end{array} & \begin{array}{l}\text { alphanumeric name of relate you want to establish } \\ \text { pathname or database table name of the related file }\end{array} \\ \begin{array}{l}\text { Database name: } \\ \text { Info item: }\end{array} & \text { name of the database in which the related file is stored } \\ \text { the item name in an INFO data file from which the relate is performed } \\ \text { Relate type: }\end{array} \quad \begin{aligned} & \text { the field in the related table which is related to the INFO item } \\ & \text { the type of relate performed-one of the following four: LINEAR, } \\ & \text { ORDERED, LINK, TABLE. LINEAR is the slowest, but the simplest to } \\ & \text { apply. (Please consult ARC/INFO online help topic such as 'working } \\ & \text { with tables' for help on selection of relate type) } \\ & \text { the access rights to the related file: RW, or RO, or AUTO }\end{aligned}$

Example (lines):

Arc: relate add

Relation name: line_dictionary

Table identifier: lines.rel

Database name: info

INFO item: 1-tag

Relate column: 1-tag

Relate type: linear

Relate access: rw

Lines-Lines are recorded as strings of arcs and are described in an arc attribute (.aat) table in Appendix I. They represent contacts and faults which define the boundaries of map units and map boundaries.

Polygons - Geologic map units (polygons) are described in the polygon attribute table in Appendix I. Using a system developed under the Southern California Areal Mapping Project (SCAMP), geologic maps can be encoded with detailed, polygon-specific geologic information on a polygon-by-polygon basis, so that within a quadrangle, lateral variations in a particular map unit can be recorded in the map database. Detailed encoding of polygons is not available in this version of the Devore quadrangle, but will be in the next version. For traditional descriptions of the map units, see the Portable Document Format file devre_map.pdf. A list of all map units in the database is given in Appendix I.

Points-Point information (attitudes of planar and linear features, and line ornamentation) is recorded as coordinate and related information and is given in Appendix I.

\section{REFERENCES}

Environmental Systems Research Institute, Inc, 1991, ARC/INFO command references 6.0: Proprietary software manual 
Matti, J.C., Powell, R.E., Miller, F.K., Kennedy, S.A., Ruppert, K.R., Morton, G.L., and Cossette, P.M., 1998a, Geologic-line attributes for digital geologic map databases produced by the Southern California Areal Mapping Project (SCAMP), Version 1.0: U.S.Geological Survey Open-File Report 97-861

Matti, J.C., Miller, F.K., Powell, R.E., Kennedy, S.A., Bunyapanasarn, T.P., Koukladas, Catherine, Hauser, R.M., and Cossette, P.M., 1998b, Geologic-point attributes for digital geologic map databases produced by the Southern California Areal Mapping Project (SCAMP), Version 1.0: U.S.Geological Survey Open-File Report 97-859

\author{
$\underline{\text { APPENDIX I }}$ \\ Identification_Information: \\ Identification_Information: \\ Citation: \\ Citation_Information: \\ Originator: Douglas M. Morton \\ Originator: Jonathan C. Matti \\ Publication_Date: 2001 \\ Title: Geologic Map of the Devore 7.5' quadrangle, San Bernardino County, California \\ Edition: Version 1.0 \\ Geospatial_Data_Presentation_Form: vector digital data \\ Series_Information: \\ Series_Name: U.S. Geological Survey Open-File Report \\ Issue_Identification: USGS OF 01-173 \\ Publication_Information: \\ Publication_Place: Menlo Park, California \\ Publisher: U.S. Geological Survey \\ Online_Linkage: URL:http://geopubs.wr.usgs.gov/open-file/of01-173
}

Description:

\begin{abstract}
:
This data set maps and describes the geology of the Devore 7.5' quadrangle, San Bernardino County, California. Created using Environmental Systems Research Institute's ARC/INFO software, the data base consists of the following items: (1) a map coverage containing geologic contacts and units, (2) attribute tables for geologic units (polygons), contacts (arcs), and site-specific data (points). In addition, the data set includes the following graphic and text products: (1) A PostScript graphic plot-file containing the geologic map, topography, cultural data, a Correlation of Map Units (CMU) diagram, a Description of Map Units (DMU), an index map, a regional geologic and structure map, and a key for point and line symbols; (2) PDF files of this Readme (including the metadata file as an appendix), Description of Map Units (DMU), and the graphic produced by the PostScript plot file.
\end{abstract}

The Devore quadrangle straddles part of the boundary between two major physiographic provinces of California, the Transverse Ranges Province to the north and the Peninsular Ranges Province to the south. The north half of the quadrangle includes the eastern San Gabriel Mountains and a small part of the western San Bernardino Mountains, both within the east-central part of the Transverse Ranges Province. South of the Cucamonga and San Andreas Fault zones, the extensive alluviated area in the south half of the quadrangle lies within the upper Santa Ana River Valley, and represents the northernmost part of the Peninsular Ranges Province. 
There are numerous active faults within the quadrangle, including right-lateral strike-slip faults of the San Andreas Fault system, which dominate the younger structural elements, and separate the San Gabriel from the San Bernardino Mountains. The active San Jacinto Fault zone projects toward the quadrangle from the southeast, but its location is poorly constrained not only within the quadrangle, but for at least several kilometers to the southeast. As a result, the interrelation between it, the Glen Helen Fault, and the probable easternmost part of the San Gabriel Fault is intrepretive. Thrust faults of the Cucamonga Fault zone along the south margin of the San Gabriel Mountains, represent the rejuvinated eastern end of a major old fault zone that bounds the south side of the western and central Transverse Ranges (Morton and Matti, 1993). Rejuvenation of this old fault zone, including the Cucamonga Fault zone, is apparently in response to compression in the eastern San Gabriel Mountains resulting from initiation of right-lateral slip on the San Jacinto Fault zone in the Peninsular Ranges.The structural grain within the San Gabriel Mountains, as defined by basement rocks, is generally east striking. Within the Devore quadrangle, these basement rocks include a Paleozoic (?) schist, quartzite, and marble metasedimentary sequence, which occurs as discontinuous lenses and septa within Cretaceous granitic rocks. Most of the granitic rocks are of tonalitic composition, and much of them are mylonitic. South of the granitic rocks is a complex assemblage of Proterozoic (?) metamorphic rocks, at least part of which is metasedimentary. The assemblage was metamorphosed to upper amphibolite and lower granulite grade, and subsequently remetamorphosed to a lower metamorphic grade. It is also intensely deformed by mylonitization which is characterized by an east striking, north dipping foliation, and by a pronounced lineation that plunges shallowly east and west.

East of Lytle Creek and west of the San Andreas Fault zone, the predominant basement lithology is Mesozoic Pelona Schist, which consists mostly of greenschist grade metabasalt and metagraywacke. Intruding the Pelona Schist, between Lytle Creek and Cajon Canyon, is the granodiorite of Telegraph Peak of Oligocene age (May and Walker, 1989). East of the San Andreas Fault in the San Bernardino Mountains, basement rocks consist of amphibolite grade gneiss and schist intermixed with concordant and discordant tonalitic rock and pegmatite. Tertiary conglomerate and sandstone occur in the Cucamonga Fault zone and in a zone 200 to $700 \mathrm{~m}$ wide between strands of the San Andreas Fault zone and localized thrust faults northeast of the San Andreas. Most of the conglomerate and sandstone within the Cucamonga Fault zone is overturned forming the north limb of an overturned syncline. Clasts in the conglomerate are not derived from any of the basement rocks in the eastern San Gabriel Mountains. Clasts in the conglomerate and sandstone northeast of the San Andreas Fault zone do not appear to be locally derived either. The south half of the quadrangle is dominated by the large symmetrical alluvial-fan emanating from the canyon of Lytle Creek, and by the complex braided stream sediments of Lytle Creek and Cajon Wash.

The San Andreas Fault is restricted to a relatively narrow zone marked by a pronounced scarp that is especially well exposed near the east margin of the quadrangle. Two poorly exposed, closely spaced, north-dipping thrust faults northeast of the San Andreas Fault have dips that appear to range from $55^{\circ}$ to near horizontal. The shallower dips probably are the result of rotation of initially steeper fault surfaces by downhill surface creep. Between the San Andreas and Glen Helen Fault zones, there are several faults that have north facing scarps, the largest of which are the east striking Peters Fault and the northwest striking Tokay Hill Fault. The Tokay Hill Fault is at least in part a reverse fault. Scarps along both faults are youthful appearing.

The Glen Helen Fault zone along the west side of Cajon Creek, is well defined by a pronounced scarp from the area north of Interstate 15, south through Glen Helen 
Regional Park; an elongate sag pond is located within the park.

The large fault zone along Meyers Canyon, between Penstock and Lower Lytle Ridges, is probably the eastward extension of the San Gabriel Fault zone that is deformed into a northwest orientation due to compression in the eastern San Gabriel Mountains (Morton and Matti, 1993). At the south end of Sycamore Flat, this fault zone consists of three discreet faults distributed over a width of $300 \mathrm{~m}$. About $2.5 \mathrm{~km}$ northwest of Sycamore Flats, it consists of a $300 \mathrm{~m}$ wide shear zone. At the north end of Penstock Ridge, the fault zone has bifurcated into four strands, which at the northwest corner of the quadrangle are distributed over a width of about one kilometer. From the northern part of Sycamore Flat, for a distance of nearly $5 \mathrm{~km}$ northwestward, a northeast dipping reverse fault is located along the east side of the probable San Gabriel Fault zone. This youthful reverse fault has locally placed the Oligocene granodiorite of Telegraph Peak over detritus derived from the granodiorite.

The Lytle Creek Fault, which is commonly considered the western splay of the San Jacinto Fault zone, is located on the west side of Lytle Creek. Lateral displacement on the Lytle Creek Fault has offset parts of the old Lytle Creek channel; this offset gravel-filled channel is best seen at Texas Hill, near the mouth of Lytle Creek, where the gravel was hydraulic mined for gold in the 1890s.

The Cucamonga Fault zone consists of a one kilometer wide zone of northward dipping thrust faults. Most splays of this fault zone dip north $25^{\circ}$ to $35^{\circ}$.

The geologic map database contains original U.S. Geological Survey data generated by detailed field observation and by interpretation of aerial photographs. This digital Open-File map supercedes an older analog Open-File map of the quadrangle, and includes extensive new data on the Quaternary deposits, and revises some fault and bedrock distribution within the San Gabriel Mountains. The digital map was compiled on a base-stable cronoflex copy of the Devore 7.5' topographic base and then scribed. This scribe guide was used to make a 0.007 mil blackline clear-film, from which lines and point were hand digitized. Lines, points, and polygons were subsequently edited at the USGS using standard ARC/INFO commands. Digitizing and editing artifacts significant enough to display at a scale of $1: 24,000$ were corrected. Within the database, geologic contacts are represented as lines (arcs), geologic units as polygons, and site-specific data as points. Polygon, arc, and point attribute tables (.pat, .aat, and .pat, respectively) uniquely identify each geologic datum.

Purpose:

The data set for the Devore 7.5' quadrangle was prepared under the U.S. Geological Survey Southern California Areal Mapping Project (SCAMP) as part of an ongoing effort to develop a regional geologic framework of southern California, and to utilize a

Geographical Information System (GIS) format to create regional digital geologic databases. These regional databases are being developed as contributions to the National Geologic Map Database of the National Cooperative Geologic Mapping Program of the USGS.

The digital geologic map database for the Devore 7.5' quadrangle has been created as a general-purpose data set that is applicable to other land-related investigations in the earth and biological sciences. For example, it can be used for groundwater studies in the San Bernardino basin, and for mineral resource evaluation studies, animal and plant habitat studies, and soil studies in the San Bernardino National Forest. The database is not suitable for site-specific geologic evaluations.

Time_Period_of_Content:

Time_Period_Information:

Range_of_Dates/Times:

Beginning_Date: 19740401 
Ending_Date: 19810801

Currentness_Reference: New data and previously published data

Status:

Progress: Complete

Maintenance_and_Update_Frequency: As needed

Spatial_Domain:

Bounding_Coordinates:

West_Bounding_Coordinate: -117.50009251

East_Bounding_Coordinate: -117.37490753

North_Bounding_Coordinate: 34.24999997

South_Bounding_Coordinate: 34.12498409

Keywords:

Theme:

Theme_Keyword_Thesaurus: None

Theme_Keyword: geologic map

Theme_Keyword: geology

Theme_Keyword: bedrock geology

Theme_Keyword: surficial geology

Theme_Keyword: San Andreas Fault

Theme_Keyword: San Jacinto Fault

Theme_Keyword: Cucamonga Fault

Theme_Keyword: San Gabriel Mountains

Theme_Keyword: Pelona Schist

Place:

Place_Keyword_Thesaurus: None

Place_Keyword: California

Place_Keyword: San Bernardino County

Place_Keyword: Devore 7.5' quadrangle

Access_Constraints: None

Use_Constraints:

The Devore 7.5' geologic-map database should be used to evaluate and understand the geologic character of the Devore 7.5' quadrangle as a whole. The data should not be used for purposes of site-specific land-use planning or site-specific geologic evaluations. The database is sufficiently detailed to identify and characterize geologic materials and structures. However, it is not sufficiently detailed for site-specific determinations.

Use of this digital geologic map database should not violate the spatial resolution of the data. Although the digital form of the data removes the constraint imposed by the scale of a paper map, the detail and accuracy inherent in map scale are also present in the digital data. The fact that this database was compiled and edited at a scale of $1: 24,000$ means that higher resolution information may not have been uniformly retained in the dataset. Plotting at scales larger than 1:24,000 will not yield greater real detail, although it may reveal fine-scale irregularities below the intended resolution of the database. Similarly, although higher resolution data is incorporated in parts of the map, the resolution of the combined output will be limited by the lower resolution data.

Point_of_Contact:

Contact_Information:

Contact_Person_Primary: 


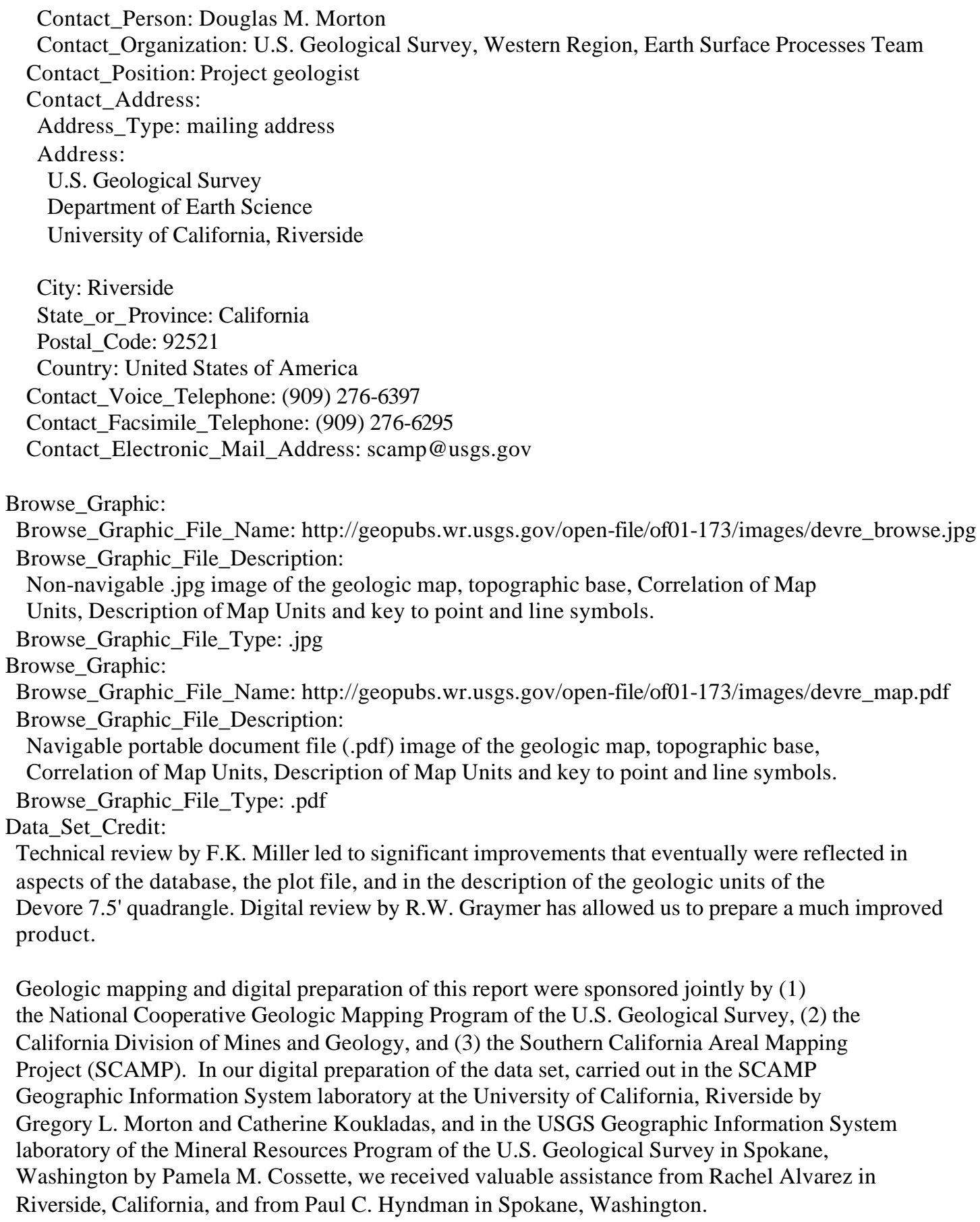

Geologic mapping and digital preparation of this report were sponsored jointly by (1) the National Cooperative Geologic Mapping Program of the U.S. Geological Survey, (2) the California Division of Mines and Geology, and (3) the Southern California Areal Mapping Project (SCAMP). In our digital preparation of the data set, carried out in the SCAMP Geographic Information System laboratory at the University of California, Riverside by Gregory L. Morton and Catherine Koukladas, and in the USGS Geographic Information System laboratory of the Mineral Resources Program of the U.S. Geological Survey in Spokane, Washington by Pamela M. Cossette, we received valuable assistance from Rachel Alvarez in Riverside, California, and from Paul C. Hyndman in Spokane, Washington.

Native_Data_Set_Environment:

SunOS, 5.7, sun4u UNIX

ARC/INFO version 7.2.1

Cross_Reference:

Citation_Information:

Originator: D.M. Morton

Originator: J.C. Matti

Publication_Date: 1991 
Title: Geologic map of the Devore 7.5' quadrangle, San Bernardino County, California Edition: Version 1.0

Geospatial_Data_Presentation_Form: paper map

Series_Information:

Series_Name: U.S. Geological Survey Open-File Report

Issue_Identification: USGS OF 90-695

Publication_Information:

Publication_Place: Menlo Park, California

Publisher: U.S. Geological Survey

Data_Quality_Information:

Attribute_Accuracy:

Attribute_Accuracy_Report:

Geologic-map units in the Devore quadrangle database were described using standard field methods. Consistent with these methods, the database author has assigned standard geologic attributes to geologic lines, points, and polygons identified in the database.

Nation-wide geologic-map accuracy standards have not been developed and adopted by the U.S. Geological Survey and other earth-science entities. Until such standards are adopted, the SCAMP project has developed internal map-accuracy standards for 1:24,000-scale geologic maps produced by the project.

Geologic lines and points on 1:24,000 scale geologic maps are judged to meet SCAMP's internal map-accuracy standards if they are located to within $+/-15$ meters, relative to topographic or cultural features on the base map.

Lines and points that meet (or may not meet) this SCAMP internal map-accuracy standard are identified both in the digital database and on derivative geologic-map plots. Within the database, line and point data that are judged to meet the SCAMP internal map-accuracy standard are denoted by the attribute code .MEE. (meets) in the appropriate data table; line and point data that may not meet the SCAMP internal map-accuracy standard are denoted by the attribute code .MNM. (may not meet).

On any derivative geologic-map plot, line data that are judged to meet the SCAMP internal map-accuracy standard are denoted by solid lines; line data that may not meet the SCAMP internal map-accuracy standard are denoted by dashed or dotted lines. There is no cartographic device for denoting the map-accuracy for geologic-point data (eg. symbols representing bedding, foliation, lineations, etc.).

Logical_Consistency_Report:

Polygon and chain-node topology present.

The areal extent of the map is represented digitally by an appropriately projected (Polyconic projection), mathematically generated box. Consequently, polygons intersecting the lines that comprise the map boundary are closed by that boundary. Polygons internal to the map boundary are completely enclosed by line segments which are themselves a set of sequentially numbered coordinate pairs. Point data are represented by coordinate pairs.

Completeness_Report:

The geologic map and digital database of the Devore 7.5' quadrangle contain new data that have been subjected to rigorous review and are a substantially complete representation of the current state of knowledge concerning the geology of the quadrangle.

Positional_Accuracy:

Horizontal_Positional_Accuracy: 
Horizontal_Positional_Accuracy_Report:

The maximum transformation RMS error acceptable for 7.5' quadrangle transformation and data input is 0.003 (7.6 meters). Horizontal positional accuracy was checked by visual comparison of hard-copy plots with base-stable source data.

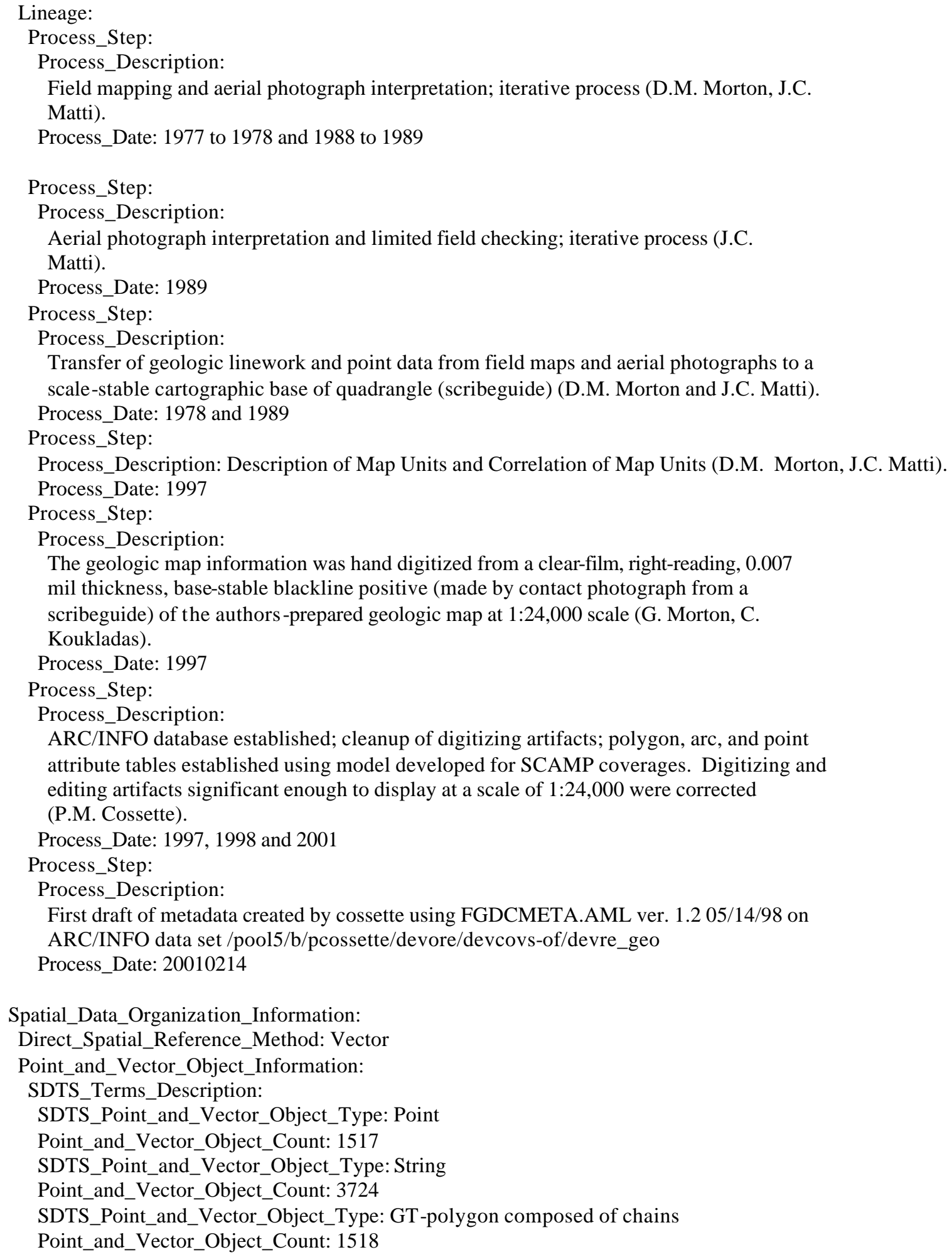


Spatial_Reference_Information:

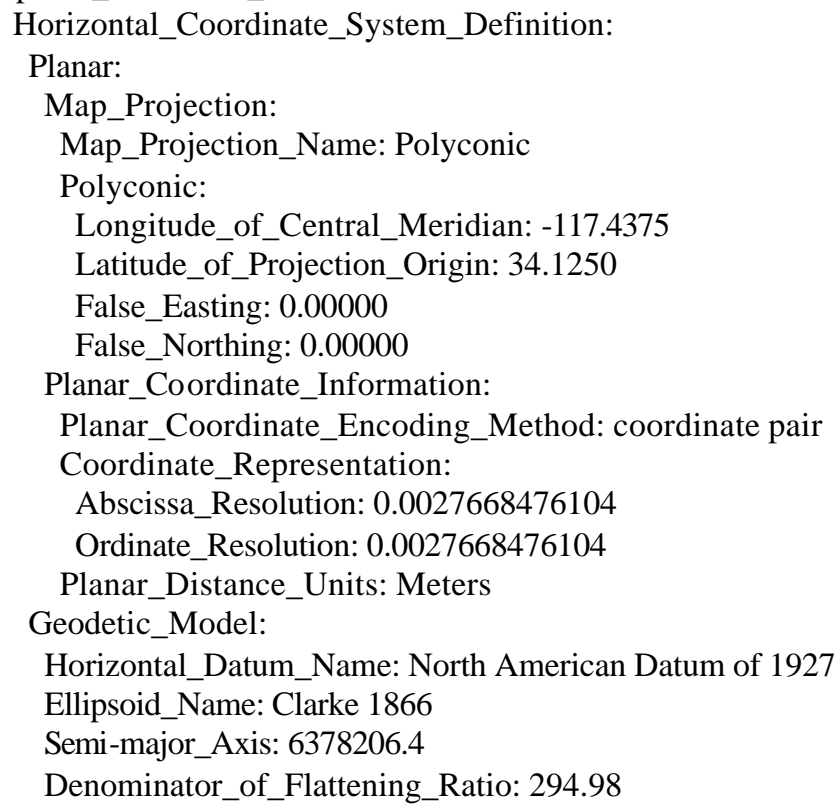

Entity_and_Attribute_Information:

Overview_Description:

Entity_and_Attribute_Overview:

Version 1.0 of the Devore 7.5' quadrangle comprises three ARC/INFO coverages, of which two contain geologic data and one contains cartographic features: devre_geo (geology), devre_str (structural point data), and devre_ldr (annotation leaders). Line and point identities are recorded in the .aat and pat tables using a system of identity codes. Two INFO tables, lines.rel and points.rel provide a full description of each of the geologic line and point codes in the database. A full source citation is provided in the Entity_and Attribute_Detail_Citation section of this metadata document.

Geologic data represented by line entities and the polygons they delineate are contained in the coverage DEVRE_GEO. For display purposes, the geology coverage contains two annotation subclasses: anno.geo contains unit labels, and anno.fault contains formal, fault names.

Geological point data includes site-specific information describing the types and the orientation of bedding, foliation, and lineations. One annotation subclass is included in the geologic points coverage, DEVRE_STR: anno.dip displays the respective dip and plunge values associated with individual point data.

Entity_and_Attribute_Detail_Citation:

A complete description of the polygon, line, and point data coding schemes is available in U.S. Geological Survey Open-File Reports OFR 97-859, OFR 97-860, and OFR 97-861 (full source citations follow):

Matti, J.C., Miller, F.K., Powell, R.E., Kennedy, S.A., Bunyapanasarn, T.P., Koukladas, Catherine, Hauser, R.M., and Cossette, P.M., 1997b, Geologic-point attributes for digital geologic-map databases produced by the Southern California Areal Mapping Project (SCAMP), Version 1.0: U.S.Geological Survey Open-File Report 97-859

Matti, J.C., Miller, F.K., Powell, R.E., Kennedy, S.A., and Cossette, P.M., 1997c, Geologic-polygon attributes for digital geologic-map databases produced by the Southern California Areal Mapping Project (SCAMP), Version 1.0: U.S.Geological Survey Open-File Report 97-860 
Matti, J.C., Powell, R.E., Miller, F.K., Kennedy, S.A., Ruppert, K.R., Morton, G.L., and

Cossette, P.M., 1997a, Geologic-line attributes for digital geologic-map databases

produced by the Southern California Areal Mapping Project (SCAMP), Version 1.0:

U.S.Geological Survey Open-File Report 97-861

Detailed_Description:

Entity_Type:

Entity_Type_Label: devre_geo.pat

Entity_Type_Definition:

Geologic units (LABL) and their corresponding names (NAME) identified in the Devore

7.5'quadrangle

Attribute:

Attribute_Label: SHDPS

Attribute_Definition: polygon color (as integer value) from shadeset scamp2.shd (included in the data package)

Attribute:

Attribute_Label: SHDFIL

Attribute_Definition:

polygon fill pattern (as integer value) from shadeset geology2.shd (included in the data package)

Attribute:

Attribute_Label: LABL

Attribute_Definition: geologic map unit label, in plain text

Attribute_Domain_Values:

Enumerated_Domain:

Enumerated_Domain_Value: Kg

Enumerated_Domain_Value_Definition: Monzogranite and granodiorite

Enumerated_Domain:

Enumerated_Domain_Value: Kgc

Enumerated_Domain_Value_Definition: Mylonitic leucogranite

Enumerated_Domain:

Enumerated_Domain_Value: Kgm

Enumerated_Domain_Value_Definition: Leucocratic muscovite monzogranite

Enumerated_Domain:

Enumerated_Domain_Value: Kmg

Enumerated_Domain_Value_Definition: Biotite monzogranite

Enumerated_Domain:

Enumerated_Domain_Value: Kt

Enumerated_Domain_Value_Definition: Tonalite of San Sevaine Lookout

Enumerated_Domain:

Enumerated_Domain_Value: Ktm1

Enumerated_Domain_Value_Definition: Mylonitized tonalite of San Sevaine Lookout

Enumerated_Domain:

Enumerated_Domain_Value: Mzgn

Enumerated_Domain_Value_Definition: Gneiss east of San Andreas Fault zone

Enumerated_Domain:

Enumerated_Domain_Value: Mzpg

Enumerated_Domain_Value_Definition: Greenstone

Enumerated_Domain:

Enumerated_Domain_Value: Mzps

Enumerated_Domain_Value_Definition: Siliceous schist

Enumerated_Domain:

Enumerated_Domain_Value: TMztp

Enumerated_Domain_Value_Definition: Pelona Schist and granodiorite of Telegraph Peak

Enumerated_Domain:

Enumerated_Domain_Value: Mzpw

Enumerated_Domain_Value_Definition: Muscovite schist 


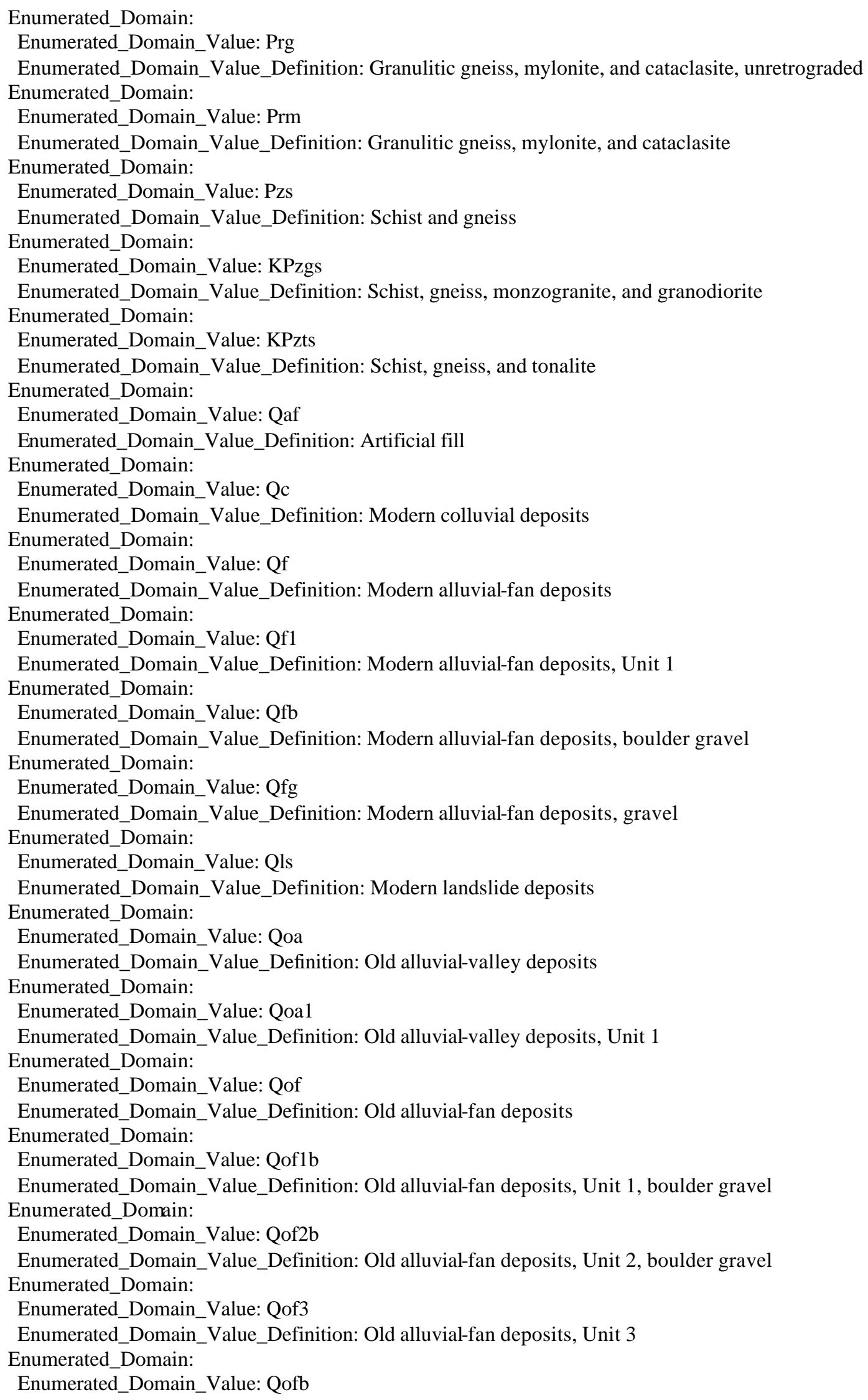


Enumerated_Domain_Value_Definition: Old alluvial-fan deposits, boulder gravel

Enumerated_Domain:

Enumerated_Domain_Value: Qols

Enumerated_Domain_Value_Definition: Old landslide deposits

Enumerated_Domain:

Enumerated_Domain_Value: Qsw

Enumerated_Domain_Value_Definition: Modern slopewash deposits

Enumerated_Domain:

Enumerated_Domain_Value: Qt

Enumerated_Domain_Value_Definition: Modern talus deposits

Enumerated_Domain:

Enumerated_Domain_Value: Quarry

Enumerated_Domain_Value_Definition: Disturbed ground

Enumerated_Domain:

Enumerated_Domain_Value: Qvof

Enumerated_Domain_Value_Definition: Very old alluvial-fan deposits

Enumerated_Domain:

Enumerated_Domain_Value: Qvof1b

Enumerated_Domain_Value_Definition: Very old alluvial-fan deposits, Unit 1, boulder gravel

Enumerated_Domain:

Enumerated_Domain_Value: Qvof2

Enumerated_Domain_Value_Definition: Very old alluvial-fan deposits, Unit 2

Enumerated_Domain:

Enumerated_Domain_Value: Qvof2b

Enumerated_Domain_Value_Definition: Very old alluvial-fan deposits, Unit 2, boulder gravel

Enumerated_Domain:

Enumerated_Domain_Value: Qvof2g

Enumerated_Domain_Value_Definition: Very old alluvial-fan deposits, Unit 2, gravel

Enumerated_Domain:

Enumerated_Domain_Value: Qvofb

Enumerated_Domain_Value_Definition: Very old alluvial-fan deposits, boulder gravel

Enumerated_Domain:

Enumerated_Domain_Value: Qvolsa

Enumerated_Domain_Value_Definition: Very old landslide deposits, arenaceous

Enumerated_Domain:

Enumerated_Domain_Value: Qvowb

Enumerated_Domain_Value_Definition: Very old wash deposits, boulder gravel

Enumerated_Domain:

Enumerated_Domain_Value: Qw

Enumerated_Domain_Value_Definition: Modern wash deposits

Enumerated_Domain:

Enumerated_Domain_Value: Qw1

Enumerated_Domain_Value_Definition: Modern wash deposits, Unit 1

Enumerated_Domain:

Enumerated_Domain_Value: Qw2

Enumerated_Domain_Value_Definition: Modern wash deposits, Unit 2

Enumerated_Domain:

Enumerated_Domain_Value: Qw2b

Enumerated_Domain_Value_Definition: Modern wash deposits, Unit 2, boulder gravel

Enumerated_Domain:

Enumerated_Domain_Value: Qwb

Enumerated_Domain_Value_Definition: Modern wash deposits, boulder gravel

Enumerated_Domain:

Enumerated_Domain_Value: Qya4

Enumerated_Domain_Value_Definition: Young alluvial-valley deposits, Unit 4

Enumerated_Domain: 


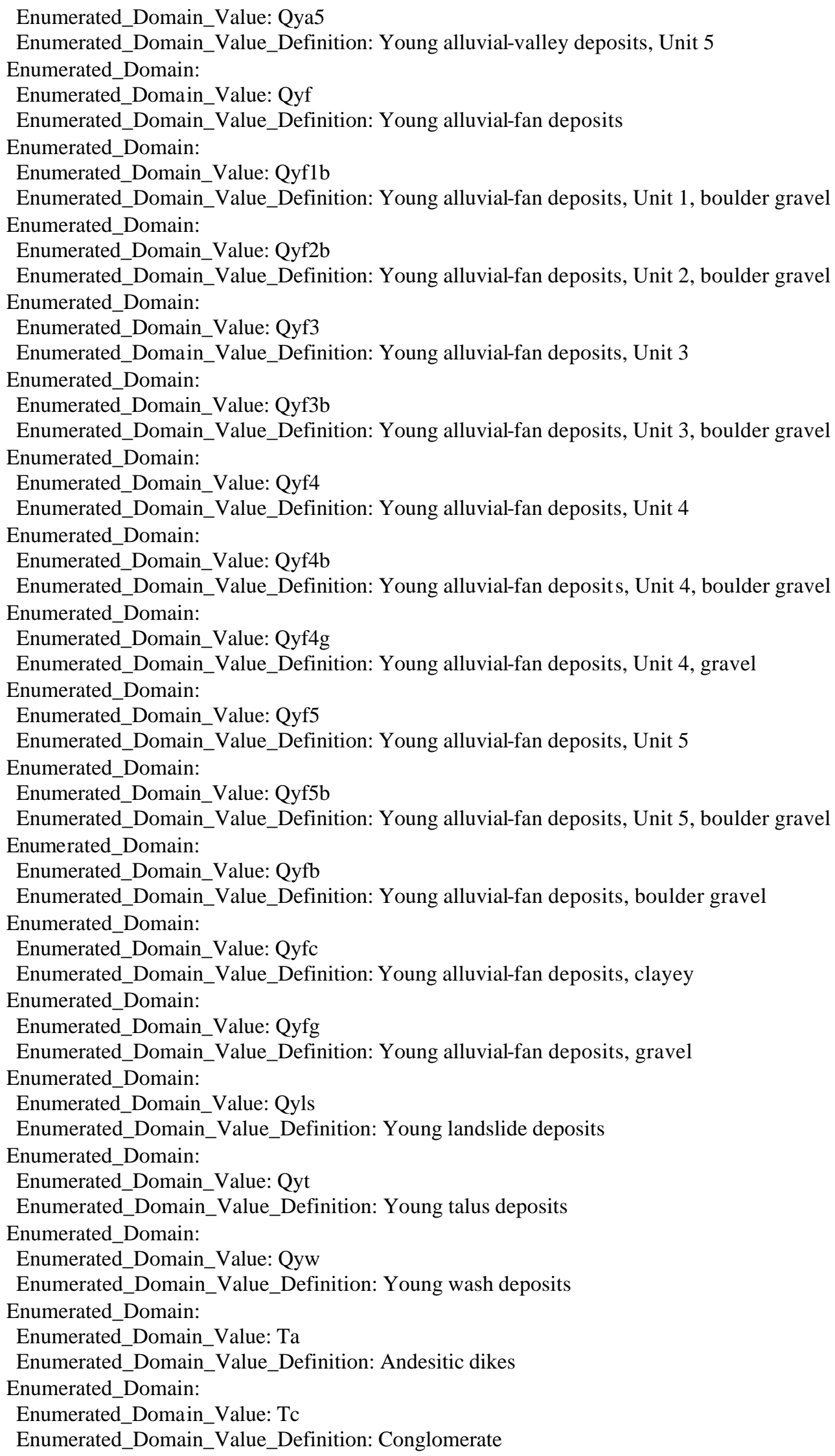




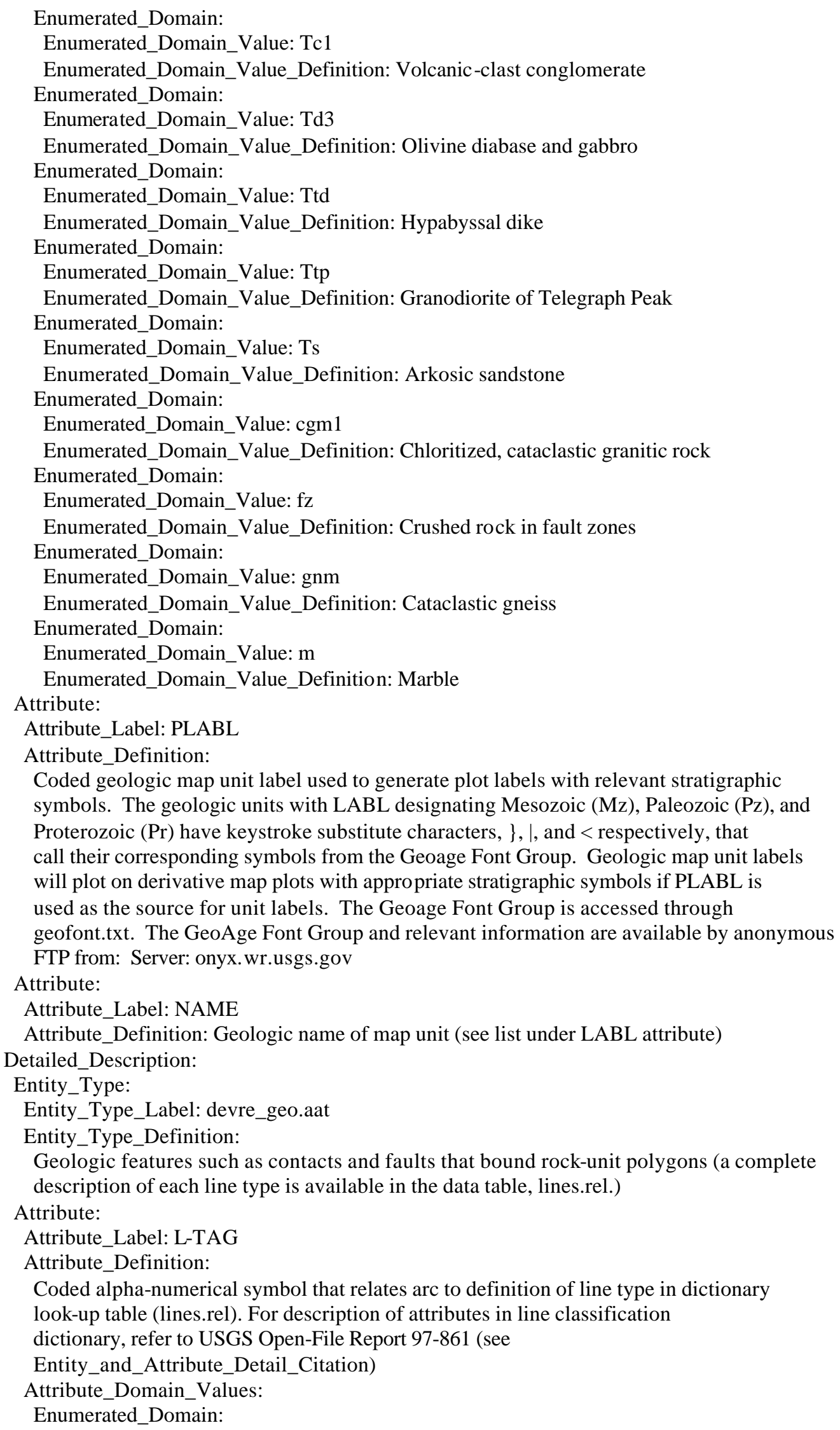


Enumerated_Domain_Value: C1

Enumerated_Domain_Value_Definition: Contact, generic, certain, location meets map accuracy standard

Enumerated_Domain:

Enumerated_Domain_Value: C100

Enumerated_Domain_Value_Definition: Contact, scratch boundary, metamorphic

Enumerated_Domain:

Enumerated_Domain_Value: C17

Enumerated_Domain_Value_Definition: Contact, landslide, certain, location meets map accuracy standard

Enumerated_Domain:

Enumerated_Domain_Value: C18

Enumerated_Domain_Value_Definition: Contact, landslide, certain, location may not meet map accuracy standard

Enumerated_Domain:

Enumerated_Domain_Value: C19

Enumerated_Domain_Value_Definition: Contact, landslide, inferred, location may not meet map accuracy standard

Enumerated_Domain:

Enumerated_Domain_Value: C20

Enumerated_Domain_Value_Definition:CContact, landslide, concealed, location may not meet map accuracy standard

Enumerated_Domain:

Enumerated_Domain_Value: C29

Enumerated_Domain_Value_Definition: Contact, sedimentary, certain, location meets map accuracy standard

Enumerated_Domain:

Enumerated_Domain_Value: C30

Enumerated_Domain_Value_Definition: Contact, sedimentary, certain, location may not meet map accuracy standard

Enumerated_Domain:

Enumerated_Domain_Value: C31 standard

Enumerated_Domain_Value_Definition: Contact, sedimentary, inferred, location may not meet map accuracy

Enumerated_Domain:

Enumerated_Domain_Value: C32

Enumerated_Domain_Value_Definition: Contact, sedimentary, concealed, location may not meet map accuracy standard

Enumerated_Domain:

Enumerated_Domain_Value: C34

Enumerated_Domain_Value_Definition: Contact, sedimentary, questionable, location may not meet map accuracy standard

Enumerated_Domain:

Enumerated_Domain_Value: C37

Enumerated_Domain_Value_Definition:

Contact, sedimentary, separates terraced alluvial units, certain, location meets map accuracy standard

Enumerated_Domain:

Enumerated_Domain_Value: C38

Enumerated_Domain_Value_Definition:

Contact, sedimentary, certain, separates terraced alluvial units, location may not meet map accuracy standard

Enumerated_Domain:

Enumerated_Domain_Value: C49

Enumerated_Domain_Value_Definition: Contact, igneous, location meets map accuracy standard

Enumerated_Domain:

Enumerated_Domain_Value: C50

Enumerated_Domain_Value_Definition: Contact, igneous, location may not meet map accuracy standard

Enumerated_Domain: 
Enumerated_Domain_Value: C51

Enumerated_Domain_Value_Definition: Contact, igneous, inferred, location may not meet map accuracy standard

Enumerated_Domain:

Enumerated_Domain_Value: C66 standard

Enumerated_Domain_Value_Definition: Contact, metamorphic, certain, location may not meet map accuracy

Enumerated_Domain:

Enumerated_Domain_Value: C67

Enumerated_Domain_Value_Definition: Contact, metamorphic, inferred, location may not meet map accuracy standard

Enumerated_Domain:

Enumerated_Domain_Value: C99

Enumerated_Domain_Value_Definition: Contact, igneous, scratch boundary

Enumerated_Domain:

Enumerated_Domain_Value: CL1

Enumerated_Domain_Value_Definition: Cartographic line, map boundary

Enumerated_Domain:

Enumerated_Domain_Value: F1

Enumerated_Domain_Value_Definition: Fault, high angle, slip unspecified, location meets map accuracy standard

Enumerated_Domain:

Enumerated_Domain_Value: F11 standard

Enumerated_Domain_Value_Definition: Fault, high angle, reverse slip, location may not meet map accuracy

Enumerated_Domain:

Enumerated_Domain_Value: F13

Enumerated_Domain_Value_Definition:

Fault, high angle, slip unspecified, inferred, location may not meet map accuracy

standard

Enumerated_Domain:

Enumerated_Domain_Value: F177 standard

Enumerated_Domain_Value_Definition: Fault, thrust, older over younger, certain, location meets map accuracy

Enumerated_Domain:

Enumerated_Domain_Value: F178

Enumerated_Domain_Value_Definition: Fault, thrust, older over younger, certain, location may not meet map accuracy standard

Enumerated_Domain:

Enumerated_Domain_Value: F180

Enumerated_Domain_Value_Definition:

Fault, thrust, older over younger, concealed, location may not meet map accuracy standard

Enumerated_Domain:

Enumerated_Domain_Value: F182R

Enumerated_Domain_Value_Definition:

Fault, thrust, older over younger, questionable, location may not meet map accuracy

standard

Enumerated_Domain:

Enumerated_Domain_Value: F183R

Enumerated_Domain_Value_Definition:

Fault, thrust, older over younger, questionable, concealed, location may not meet map

accuracy standard

Enumerated_Domain:

Enumerated_Domain_Value: F19

Enumerated_Domain_Value_Definition: 
Fault, high angle, slip unspecified, concealed, location may not meet map accuracy standard

Enumerated_Domain:

Enumerated_Domain_Value: F193

Enumerated_Domain_Value_Definition: Fault, thrust, older over younger, scarp, certain, location meets map accuracy standard

Enumerated_Domain:

Enumerated_Domain_Value: F2

Enumerated_Domain_Value_Definition:

Fault, high angle, right lateral strike slip, certain, location meets map accuracy standard

Enumerated_Domain:

Enumerated_Domain_Value: F20

Enumerated_Domain_Value_Definition:

Fault, high angle, right lateral strike slip, concealed, location may not meet map accuracy standard

Enumerated_Domain:

Enumerated_Domain_Value: F37

Enumerated_Domain_Value_Definition:

Fault, high angle, slip unspecified, questionable, concealed, location may not meet map accuracy standard

Enumerated_Domain:

Enumerated_Domain_Value: F44

Enumerated_Domain_Value_Definition:

Fault, high angle, right lateral strike slip, questionable, concealed, location may not meet map accuracy standard

Enumerated_Domain:

Enumerated_Domain_Value: F49

Enumerated_Domain_Value_Definition:

Fault, high angle, slip unspecified, scarp, certain, location meets map accuracy standard

Enumerated_Domain:

Enumerated_Domain_Value: F50

Enumerated_Domain_Value_Definition:

Fault, high angle, right lateral strike slip, scarp, certain, location meets map accuracy standard

Enumerated_Domain:

Enumerated_Domain_Value: F55

Enumerated_Domain_Value_Definition:

Fault, high angle, slip unspecified, scarp, certain, location may not meet map accuracy standard

Enumerated_Domain:

Enumerated_Domain_Value: F56

Enumerated_Domain_Value_Definition:

Fault, high angle, right lateral strike slip, scarp, certain, location may not meet map accuracy standard

Enumerated_Domain:

Enumerated_Domain_Value: F61R

Enumerated_Domain_Value_Definition:

Fault, high angle, slip unspecified, scarp, questionable, location may not meet map

accuracy standard

Enumerated_Domain:

Enumerated_Domain_Value: F7

Enumerated_Domain_Value_Definition:

Fault, high angle, slip unspecified, certain, location may not meet map accuracy standard 


\section{Enumerated_Domain:}

Enumerated_Domain_Value: F8

Enumerated_Domain_Value_Definition:

Fault, high angle, right lateral strike slip, certain, location meets map accuracy standard

Enumerated_Domain:

Enumerated_Domain_Value: GF9

Enumerated_Domain_Value_Definition:

Geomorphic feature, ground failure crown scarp, located well but may not meet map accuracy standard

Attribute:

Attribute_Label: L-SYMB

Attribute_Definition: stores appropriate line symbol value from the lineset geoscamp2.lin

Attribute:

Attribute_Label: L-NAME

Attribute_Definition: Formal name of fault

Detailed_Description:

Entity_Type:

Entity_Type_Label: devre_str.pat

Entity_Type_Definition:

Geological point data includes site-specific information describing the types and the orientation of bedding, foliation, and lineations. One annotation subclass is included in the geologic points coverage, DEVRE_STR: anno.dip displays the respective dip and plunge values associated with individual point data.

Attribute:

Attribute_Label: P-TAG

Attribute_Definition:

Coded alpha-numerical value that relates point entity to definition of point type in dictionary INFO table, points.rel. For description of attributes in point

classification dictionary, refer to USGS Open-File Report 97-859 (see

Entity_and_Attribute_Detail_Citation)

Attribute_Domain_Values:

Enumerated_Domain:

Enumerated_Domain_Value: B1

Enumerated_Domain_Value_Definition: Bedding, sedimentary, horizontal

Enumerated_Domain:

Enumerated_Domain_Value: B2

Enumerated_Domain_Value_Definition: Bedding, sedimentary, inclined

Enumerated_Domain:

Enumerated_Domain_Value: B4

Enumerated_Domain_Value_Definition: Bedding, sedimentary, vertical

Enumerated_Domain:

Enumerated_Domain_Value: B6

Enumerated_Domain_Value_Definition: Bedding, sedimentary, overturned

Enumerated_Domain:

Enumerated_Domain_Value: FC4

Enumerated_Domain_Value_Definition: Direction and dip of fault

Enumerated_Domain:

Enumerated_Domain_Value: FN42

Enumerated_Domain_Value_Definition: Foliation, metamorphic, inclined

Enumerated_Domain:

Enumerated_Domain_Value: FN43

Enumerated_Domain_Value_Definition: Foliation, metamorphic, vertical

Enumerated_Domain:

Enumerated_Domain_Value: L10

Enumerated_Domain_Value_Definition: Lineation, metamorphic, horizontal 


\section{Enumerated_Domain:}

Enumerated_Domain_Value: L22

Enumerated_Domain_Value_Definition: Lineation, metamorphic, aligned mineral grains

Enumerated_Domain:

Enumerated_Domain_Value: L66

Enumerated_Domain_Value_Definition: Lineation, unspecified

Attribute:

Attribute_Label: P-SYMB

Attribute_Definition:

Coded integer value that relates point to cartographic point symbol in markerset geoscamp2.mrk

Attribute:

Attribute_Label: P-STRIKE

Attribute_Definition: Azimuthal strike of planar feature

Attribute:

Attribute_Label: P-DIP

Attribute_Definition: Dip of planar feature

Attribute:

Attribute_Label: P-DIPDIR

Attribute_Definition: Azimuthal direction of dip of planar feature

Attribute:

Attribute_Label: P-PLUNGE

Attribute_Definition: Plunge of linear feature

Attribute:

Attribute Label: P-BEARING

Attribute_Definition: Azimuthal direction of plunge of linear feature

Detailed_Description:

Entity_Type:

Entity_Type_Label: devre_ldr.aat

Entity_Type_Definition: Annotation leaders

Attribute:

Attribute_Label: L-SYMB

Attribute_Definition:

Coded integer value (1) that relates arcs to cartographic line symbol in lineset geoscamp2.lin

Distribution_Information:

Distributor:

Contact_Information:

Contact_Organization_Primary:

Contact_Organization: U.S. Geological Survey Information Services

Contact_Address:

Address_Type: mailing address

Address: Box 25286 Denver Federal Center

City: Denver

State_or_Province: CO

Postal_Code: 80225

Country: USA

Contact_Voice_Telephone: 303-202-4700

Contact_Facsimile_Telephone: 303-202-4693

Distribution_Liability:

The U.S. Geological Survey (USGS) provides these geographic data "as is." The USGS makes no guarantee or warranty concerning the accuracy of information contained in the geographic data. The USGS further makes no warranties, either expressed or implied as to any other matter whatsoever, including, without limitation, the condition of the product, or its fitness for any particular purpose. The burden for determining fitness 
for use lies entirely with the user. Although these data have been processed successfully on computers at the USGS, no warranty, expressed or implied, is made by the USGS regarding the use of these data on any other system, nor does the fact of distribution constitute or imply any such warranty.

In no event shall the USGS have any liability whatsoever for payment of any consequential, incidental, indirect, special, or tort damages of any kind, including, but not limited to, any loss of profits arising out of use of or reliance on the geographic data or arising out of the delivery, installation, operation, or support by USGS.

This digital, geologic map database of the San Bernardino North 7.5' quadrangle, 1:24,000 map-scale, and any derivative maps thereof, is not meant to be used or displayed at any scale larger than 1:24,000 (e.g., 1:12,000).

Metadata_Reference_Information:

Metadata_Date: 20010529

Metadata_Review_Date: 2001

Metadata_Contact:

Contact_Information:

Contact_Organization_Primary:

Contact_Organization: U.S. Geological Survey

Contact_Person: Pamela M. Cossette

Contact_Position: Geographer

Contact_Address:

Address_Type: mailing address

Address:

U.S. Geological Survey

West 904 Riverside Avenue

City: Spokane

State_or_Province: Washington

Postal_Code: 99201-1087

Country: USA

Contact_Voice_Telephone: 509-368-3123

Contact_Facsimile_Telephone: 509-368-3199

Contact_Electronic_Mail_Address: pcossette @usgs.gov

Metadata_Standard_Name: FGDC Content Standard for Digital Geospatial Metadata

Metadata_Standard_Version: FGDC-STD-001-1998

Metadata_Access_Constraints: none

Metadata_Use_Constraints: none 